\title{
Synthesis, Characterization, and Thermokinetic Analysis of New Epoxy Sugar Derivative
}

\author{
Selinay Y. Erişkin, Fatma Ç. Telli, Yeliz Yıldırım, and Yeşim Salman \\ Department of Chemistry, Faculty of Science, Ege University, Bornova, 35100, İzmir, Turkey \\ Correspondence should be addressed to Yeşim Salman; azize.yesim.salman@ege.edu.tr
}

Received 26 May 2014; Revised 24 July 2014; Accepted 25 July 2014; Published 9 September 2014

Academic Editor: Cengiz Soykan

Copyright (C) 2014 Selinay Y. Erişkin et al. This is an open access article distributed under the Creative Commons Attribution License, which permits unrestricted use, distribution, and reproduction in any medium, provided the original work is properly cited.

The synthesis of 5,6-O-isopropylidene-1,2-O- $(R)$-trichloroethylidene- $\alpha$-D-glucofuranose (compound 1 ) and 5,6-O-isopropylidene1,2-O- $(R)$-trichloroethylidene-3-O-(2', $3^{\prime}$-epoxypropan-1'-yl)- $\alpha$-D-glucofuranose (compound 2$)$ was carried out. The synthesized compounds 1 and 2 were characterized by nuclear magnetic resonance $\left({ }^{1} \mathrm{H}-\mathrm{NMR}\right)$, Fourier transform infrared spectroscopy (FTIR), and thermogravimetric analysis (TG). The FTIR and ${ }^{1} \mathrm{H}$ NMR spectra showed that the epoxy group in compound 2 was attached by means of a nucleophilic substitution reaction. The activation energies for thermal degradation of compounds 1 and 2 were calculated from their TG data by using the Kissinger-Akahira-Sunose (KAS) and Tang methods.

\section{Introduction}

Epoxides are versatile intermediates in organic synthesis. Not only are these compounds easily prepared from a variety of starting materials, but also the inherent polarity and strain of their three-membered ring make them susceptible to reaction with a large number of reagents: electrophiles, nucleophiles, acids, bases, reducing agents, and some oxidizing agents [1].

Chiral oxiranes are very important building blocks for the synthesis of enantiomerically pure complex molecules of biologically active compounds [1-3]. Carbohydrates contain several functional groups and stereogenic centres in one molecular unit, which allows the use of carbohydrates as tools in stereochemical differentiations, as starting materials in exchiral pool syntheses of interesting enantiopure compounds [4], as chiral templates in asymmetric transformations [5], and as chiral auxiliaries in stereoselective synthesis $[6,7]$.

Oxiranes are key intermediates in the asymmetric synthesis of chiral 1,2-difunctionalized compounds of biological and pharmacological interest, such as $\alpha$-hydroxy- $\beta$-amino acids derived from isoserine, which are important members of the $\beta$-amino acid family. Isoserine derivatives constitute an essential fragment in natural products of high therapeutic value [3], such as Taxol (an anticancer agent), whose side chain is $\mathrm{N}$-acyl-(2R,3S)-phenylisoserine; bestatin (a dipeptide modifier of the immune response), in which one of the amino acids is $(2 S, 3 R)$-2-hydroxy-3-amino-3-phenylbutyric acid, and the kinostatins (potent inhibitors of the HIV-1 protease), in which one of the constituent amino acids is (2S,3S)-2-hydroxy-3-amino-3-phenylbutyric acid.

The aim of this study was to investigate the possibility of producing sugar compound (2) which might be used as a monomer for the synthesis of certain polymers. Glucose is an abundant and sustainable natural product. The chloralose derivative of glucose is also prepared easily with choral and acid catalysts such as $\mathrm{H}_{2} \mathrm{SO}_{4}$ [8]. It is not possible to make an epoxy derivative of $\alpha$-chloralose without using the protecting group (5,6-O-isopropylidene). 1,2$O$ - $(R)$-Trichloroethylidene- $\alpha$-D-glucofuranose was further acetalized with 2,2-dimethoxypropane (2,2-DMP) to give the 5,6-O-isopropylidene derivative (compound 1) [9]. This sugar derivative has only one free hydroxyl group which can be etherified. After inserting a leaving group, it can also be used in a substitution reaction. Etherification of the C-3 hydroxyl group is not easy because of the low reactivity, due to steric effects of the protecting groups. Reaction with epichlorohydrin was carried out with 5,6-O-isopropyliden-1,2-O$(R)$-trichloroethylidene- $\alpha$-D-glucofuranose (1)Figure 5. This 


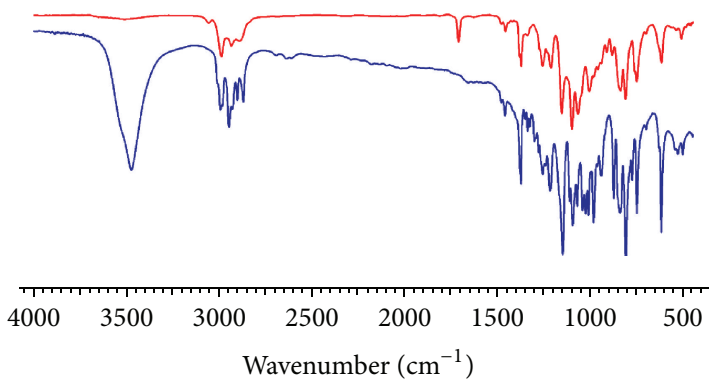

FIgURE 1: The FTIR spectrums of compounds $\mathbf{1}$ and 2.

derivative was used as a starting material which has a free C-3 hydroxyl group to react with epichlorohydrin at room temperature under basic conditions. Tetrabutylammonium bromide was used as a phase-transfer catalyst in this reaction. The structures and the stereochemistry of all of the compounds (1 and $\mathbf{2}$ ) were determined using spectroscopic techniques.

1.1. Kinetic Analysis [10-12]. Thermogravimetric analysis can be used for determining the degradation kinetics of a lot of compounds. In general, the thermal degradation reaction of a solid compound can be shown as

$$
\mathrm{A}_{\text {solid }} \longrightarrow \mathrm{B}_{\text {solid }}+\mathrm{C}_{\text {gas }} \text {, }
$$

where $\mathrm{A}$ is the starting material and $\mathrm{B}_{\text {solid }}$ and $\mathrm{C}_{\text {gas }}$ are the solid residue and the gaseous products, respectively.

The thermal degradation kinetics of the compounds is generally expressed by the following typical kinetic equation:

$$
r=\frac{d \alpha}{d t}=k(T) \times f(\alpha),
$$

where $T$ is the absolute temperature $(\mathrm{K}) ; \alpha$ is the conversion per unit time $(t)$; and $f(\alpha)$ is the conversion function which represents the reaction model. The degree of conversion $(\alpha)$ is calculated by (3), where $m_{o}, m_{t}$, and $m_{f}$ are the weights of sample before degradation at time $t$ and after complete degradation, respectively:

$$
\alpha=\frac{m_{o}-m_{t}}{m_{o}-m_{f}} .
$$

$k$ is the reaction constant which can be expressed by the Arrhenius equation:

$$
k(T)=A_{o} e^{-(E / R T)},
$$

where $A$ is called the preexponential factor, $E$ is the activation energy, and $R$ is the gas constant.

By combining (2) and (4), the following equation is obtained:

$$
\frac{d \alpha}{d t}=A_{o} e^{-(E / R T)} \times f(\alpha)
$$

According to the kinetic theory for the nonisothermal decomposition reactions, the fractional conversion $\alpha$ is expressed as a function of temperature which depends on the time of heating. Thus, the heating rate $(\beta)$ can be described as

$$
\beta=\frac{d T}{d t} .
$$

As a result, (5) can be modified as follows:

$$
\frac{d \alpha}{d T}=\left(\frac{1}{\beta}\right) A_{o} e^{-(E / R T)} \times f(\alpha) .
$$

Equations (5) and (7) are the basis for the many equations derived to evaluate thermal analysis data.

1.2. Kissinger-Akahira-Sunose (KAS) Method [13, 14]. The KAS method is based on the following equation:

$$
\ln \left(\frac{\beta}{T^{2}}\right)=\frac{\ln A R}{E g(\alpha)}-\left(\frac{E}{R T}\right),
$$

where the plots of $\ln \left(\beta / T^{2}\right)$ versus $1000 / T$ for the several $\alpha$ values give straight lines with the slope of $-E / R$ which give the corresponding $E$ values.

1.3. Tang Method [15]. The Tang method is based on the following equation:

$$
\begin{aligned}
\ln \left(\frac{\beta}{T^{1.894661}}\right)= & \frac{\ln A E}{R g(\alpha)}+3.635041 \\
& -1.894661 \ln E-\left(\frac{1.001450 E}{R T}\right) .
\end{aligned}
$$

Here, the plot of $\ln \left(\beta / T^{1.894661}\right)$ versus $1000 / T$ can give $E$ from the slope.

\section{Results and Discussion}

The FTIR spectra of compounds $\mathbf{1}$ and $\mathbf{2}$ are shown in Figure 1. The peak assignments in the FTIR spectrum of compound 1 are as follows: $\mathrm{C}-\mathrm{H}$ in $\mathrm{CH}_{3}$ and $\mathrm{C}-\mathrm{H}$ in $\mathrm{CH}_{2}$ at $2800-$ $3000 \mathrm{~cm}^{-1} ; \mathrm{C}\left(\mathrm{CH}_{3}\right)_{3}$ in isopropylidene protective group at $1374 \mathrm{~cm}^{-1}$; C-O-C peak in the sugar ring at $1150 \mathrm{~cm}^{-1}$; and $\mathrm{C}-\mathrm{Cl}$ peaks of trichloroethylidene protective group at 827 and $811 \mathrm{~cm}^{-1}$. Finally, the absorption band at $3473 \mathrm{~cm}^{-1}$ corresponds to the presence of the $\mathrm{C}-3 \mathrm{OH}$ group.

The FTIR spectrum of compound 2 was as follows: $\mathrm{C}-$ $\mathrm{H}$ in $\mathrm{CH}_{3}$ and $\mathrm{C}-\mathrm{H}$ in $\mathrm{CH}_{2}$ at $2800-3000 \mathrm{~cm}^{-1} ; \mathrm{C}\left(\mathrm{CH}_{3}\right)_{3}$ in isopropylidene protective group at $1372 \mathrm{~cm}^{-1}$; $\mathrm{C}-\mathrm{O}-\mathrm{C}$ peak in the sugar ring at $1100 \mathrm{~cm}^{-1}$; and $\mathrm{C}-\mathrm{Cl}$ peaks of trichloroethylidene protective group at 832 and $812 \mathrm{~cm}^{-1}$. Instead of the hydroxyl peak observed in the FTIR spectrum of compound 1, an ether (C-O-C) peak at $1068 \mathrm{~cm}^{-1}$ is observed in the FTIR spectrum of compound 2.

In the ${ }^{1} \mathrm{H}$ NMR spectra of compound 2, the anomeric $\mathrm{H}-1$ proton usually appears at a low field and is a very characteristic and distinct signal. Two doublets are observed in this ${ }^{1} \mathrm{H}$ NMR spectrum. One is the $\mathrm{H}-1$ doublet at $\delta$ 6.05 and another is the $\mathrm{H}-2$ doublet at $\delta 4.74$. The coupling 


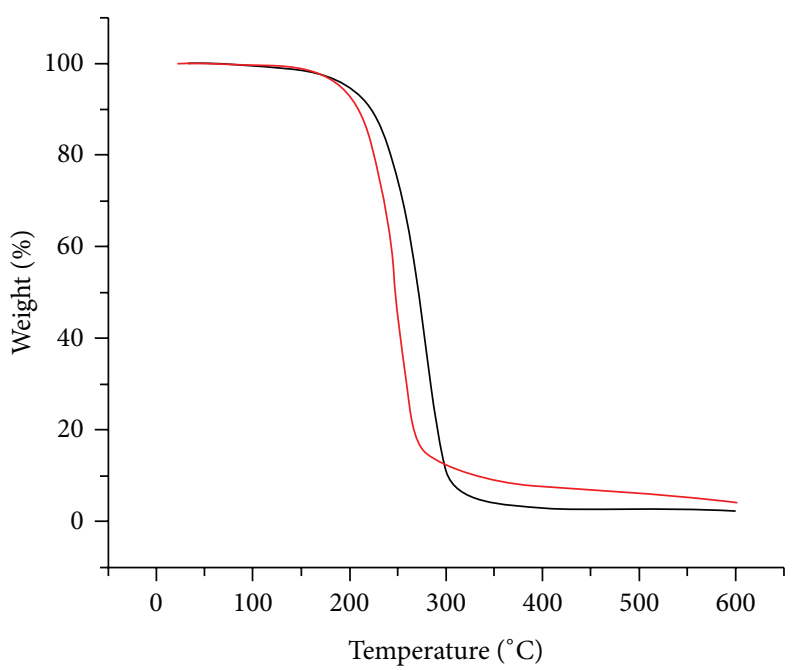

1

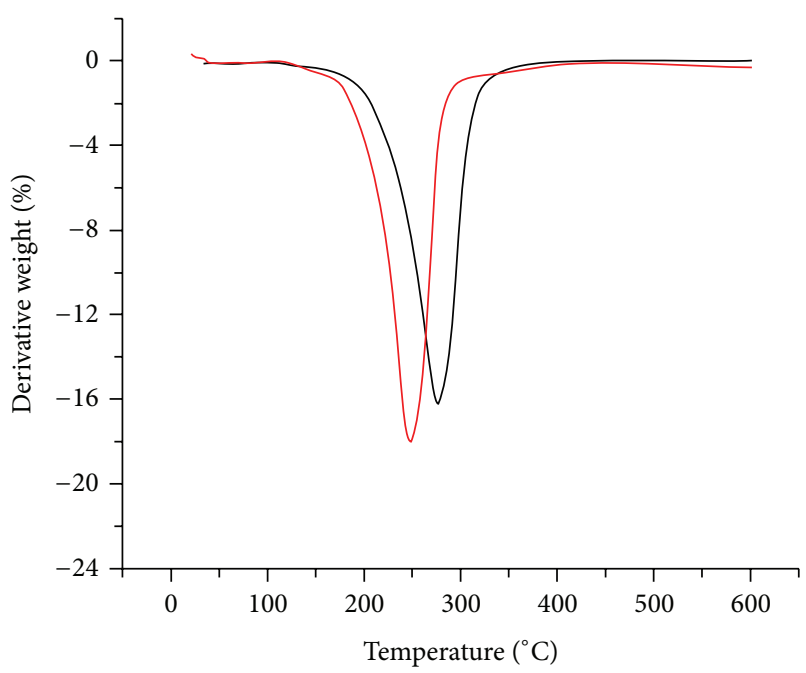

1

(a)

(b)

Figure 2: (a) Typical TG curves for compounds $\mathbf{1}$ and $\mathbf{2}$ in $\mathrm{N}_{2}$ atmosphere at $10^{\circ} \mathrm{C} \mathrm{min}^{-1}$. (b) Typical DTG curves for compounds $\mathbf{1}$ and $\mathbf{2}$ in $\mathrm{N}_{2}$ atmosphere at $10^{\circ} \mathrm{C} \mathrm{min}^{-1}$.

constant between $\mathrm{H}-1$ and $\mathrm{H}-2$ is $4.0 \mathrm{~Hz}$ which is typical for an $\alpha$-D-furanose derivative. Due to the twisted conformation of the furanose rings, the dihedral angle between the $\mathrm{H}-2$ and $\mathrm{H}-3$ protons is usually $90^{\circ}$ and, hence, in the spectra of compound 2 , the coupling constant between $\mathrm{H}-2$ and $\mathrm{H}-3$ is $0 \mathrm{~Hz}$. The H-5 proton gives a complex multiplet at $\delta 4.65$. One of the epoxy group signals is $\mathrm{H}^{-1}{ }^{\prime}$ which is resolved into a double doublet (dd) at $\delta 3.92$ with a coupling constant between $\mathrm{H}-1^{\prime}$ and $\mathrm{H}-2^{\prime}$ of $6.4 \mathrm{~Hz}$. $\mathrm{H}-2^{\prime}$ signal is observed as a multiplet at $\delta 3.13$. The $\mathrm{H}-3^{\prime}$ signals are resolved giving a dd signal at $\delta 2.80$ with a coupling constant between $\mathrm{H}-1^{\prime}$ and $\mathrm{H}-2^{\prime}$ of $11.6 \mathrm{~Hz}$. The isopropylidene methyl groups resonate at $\delta 1.39$ and 1.33. Finally, the trichloroethylidene acetal proton $\left(\mathrm{HCCl}_{3}\right)$ gives a signal at $\delta 5.28$.

2.1. Thermogravimetric Analysis of the Compounds (1 and 2). Figures 2(a) and 2(b) show the TG and DTG thermograms of compound 1 and compound 2 under nitrogen atmosphere over a temperature range from 30 to $600^{\circ} \mathrm{C}$ with a heating rate of $10^{\circ} \mathrm{C} \mathrm{min}^{-1}$, respectively. The derivative of the thermogram with respect to temperature, also known as a differential thermogram or a DTG, shows the maximum rate of compound decomposition $\left(T_{\max }\right)$. The initial $\left(T_{i}\right)$ and maximum $\left(T_{\max }\right)$ degradation temperatures related to the thermograms are summarized in Table 1.

As far as thermal degradation of compounds is concerned, only one degradation stage was observed. The $T_{\max }$ of compound 1 was about $276^{\circ} \mathrm{C}$ while that of compound 2 was $248^{\circ} \mathrm{C}$. Thus, these results show that the thermal stability of compound 1 was approximately $28^{\circ} \mathrm{C}$ higher than that of compound 2. Obviously, it is the epoxy unit, the critical component of the compound, which decreases the thermal
TABLE 1: Initial $\left(T_{i}\right)$ and maximum $\left(T_{\max }\right)$ degradation temperatures for the thermal degradation of the compounds.

\begin{tabular}{lcc}
\hline Compound number & $T_{i}\left({ }^{\circ} \mathrm{C}\right)$ & $T_{\max }\left({ }^{\circ} \mathrm{C}\right)$ \\
\hline $\mathbf{1}$ & 154 & 276 \\
$\mathbf{2}$ & 152 & 248 \\
\hline
\end{tabular}

stability. In order to obtain detailed information related to the thermal stability of the compounds, the activation energy of the degradation was calculated using the KAS and Tang methods. The KAS and Tang methods were used to analyze the TG data of the compounds because they were independent of any thermal degradation mechanism.

2.2. Thermal Degradation Kinetics of the Compounds (1 and 2). Compounds 1 and $\mathbf{2}$ were heated thermogravimetrically under various heating rates such as $5,10,15$, and $20^{\circ} \mathrm{C} \mathrm{min}{ }^{-1}$ in a temperature range of 30 to $600^{\circ} \mathrm{C}$ to determine their thermal degradation activation energies. The TG curves obtained for compounds $\mathbf{1}$ and $\mathbf{2}$ are shown in Figures 3(a) and 3(b), respectively. The individual degradation behavior of each compound was analogous at all heating rates as seen from the figure. The activation energies for the compounds were estimated by the KAS and Tang methods.

The average activation energies for compounds $\mathbf{1}$ and $\mathbf{2}$ were found to be 96 and $69 \mathrm{~kJ} \mathrm{~mol}^{-1}$, respectively, by means of the KAS method. By comparison, the average activation energies when calculated by the Tang method for compounds $\mathbf{1}$ and $\mathbf{2}$ were 113 and $87 \mathrm{~kJ} \mathrm{~mol}^{-1}$, respectively. The activation energies determined by the KAS and Tang methods indicate that the thermal stability of compound $\mathbf{1}$ has a significantly 


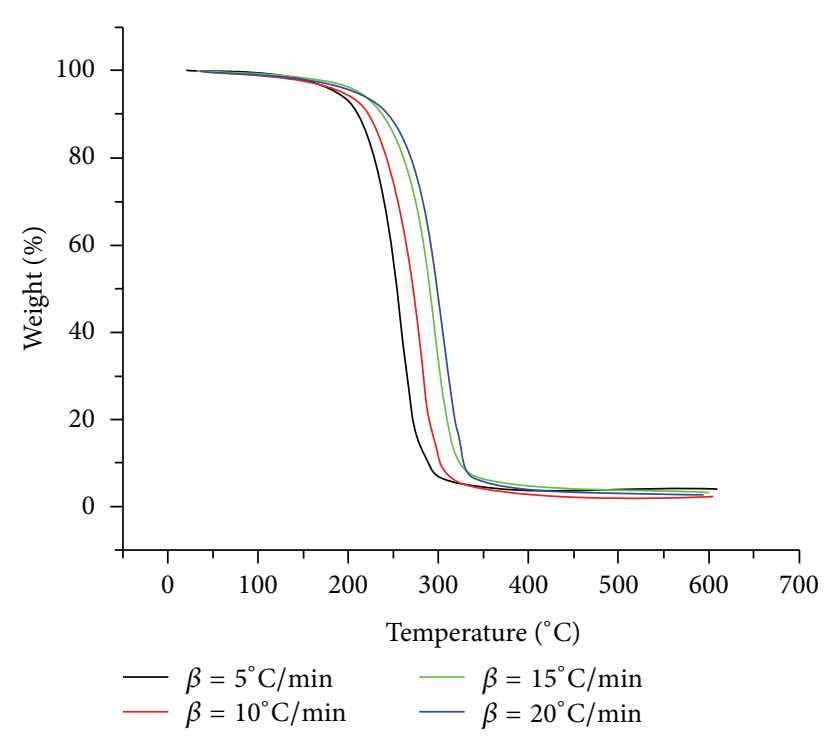

(a)

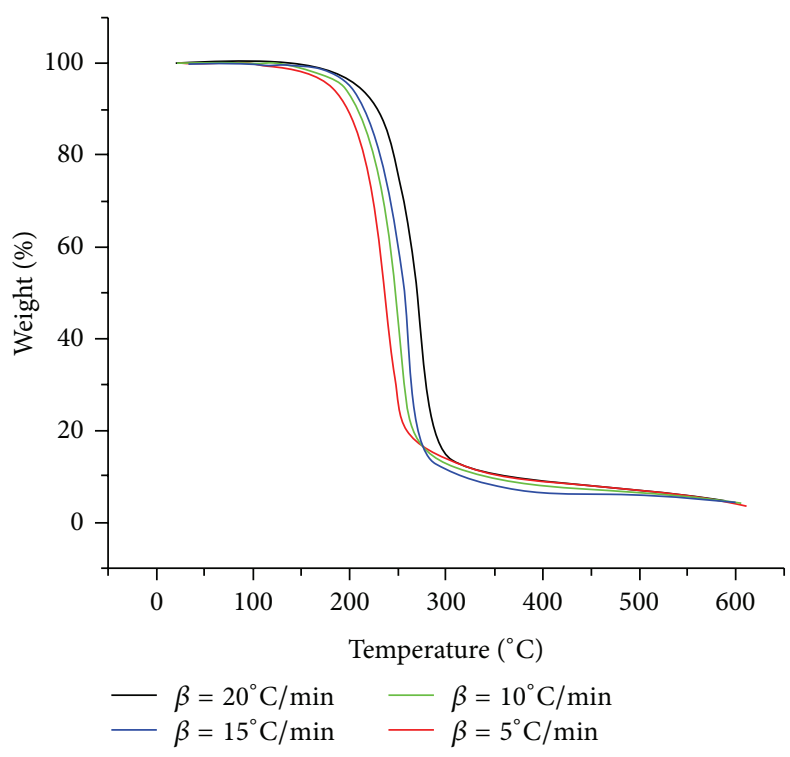

(b)

Figure 3: (a) The TG thermograms of compound $\mathbf{1}$ in argon atmosphere at different heating rates $\left(5,10,15\right.$, and $\left.20^{\circ} \mathrm{C} \mathrm{min}{ }^{-1}\right) .(\mathrm{b}) \mathrm{The} \mathrm{TG}$ thermograms of compound $2 \mathrm{in}$ argon atmosphere at different heating rates $\left(5,10,15\right.$, and $\left.20^{\circ} \mathrm{C} \mathrm{min}{ }^{-1}\right)$.

higher $E$ value than that of compound 2. Thus, it is shown that the addition of the epoxy group to the structure decreases the thermal stability.

The plot of $E$ versus the degree of conversion is commonly used to indicate the degradation mechanism, that is, whether it is one-step or more. As shown in Figure 4(a) (using the KAS method), the mechanism was almost constant up to $\alpha=0.8 ; E$ is deduced to be between 81 and $103 \mathrm{~kJ} \mathrm{~mol}^{-1}$ for compound 1 and between 75 and $65 \mathrm{~kJ} \mathrm{~mol}^{-1}$ for compound 2, which means that the compounds have only one degradation mechanism. The activation energies calculated through the Tang method for the compounds as a function of the degree of conversion (Figure 4(b)) also showed that the $E$ values were almost constant up to $80 \%$ and then increased. Thus, it can be concluded that thethermal degradation mechanisms of compound $\mathbf{1}$ and compound $\mathbf{2}$ exhibit similar behavior. Secondly, the increase in the $E$ values as a function of $\alpha$ may be attributed essentially to thermally more stable structures because of secondary reactions which had occurred during the progress of thermal degradation [16].

\section{Experimental Section}

3.1. Materials. Epichlorohydrin (stated purity 99\%), $\mathrm{NaOH}$ (stated purity $\geq 97 \%$, pellets), tetrabutylammonium bromide (stated purity 98\%), 1,2-O-(R)-trichloroethylidene- $\alpha$ $D$-glucofuranose ( $\alpha$-chloralose) (stated purity $\geq 98 \%$ ), EtOAc (stated purity 99\%), sodium hydrogen carbonate (stated purity $98 \%$ ), $\mathrm{Na}_{2} \mathrm{SO}_{4}$ (stated purity $98 \%$ ), n-hexane (stated purity $99 \%$ ), and $\mathrm{CH}_{2} \mathrm{Cl}_{2}$ (stated purity $99 \%$ ) were purchased from Merck A.G and Sigma-Aldrich. The materials and chemicals were used without any further purification.

3.2. Instrumentation. The structures of the synthesized compounds were determined by means of ${ }^{1} \mathrm{H}$ NMR (nuclear magnetic resonance) spectra of the compounds dissolved in deuterated chloroform using a Varian $400 \mathrm{MHz}$ NMR Spectrometer.

The FTIR (Fourier transform infrared spectroscopy) spectra of the compounds were obtained using a Perkin Elmer 100 FT-IR Spectrometer and the KBr pellet technique.

The TG (thermogravimetric analysis) curves were recorded using Perkin Elmer, Diamond TG/DTA. The samples were heated under $\mathrm{N}_{2}$ atmosphere over a temperature range of 30 to $600^{\circ} \mathrm{C}$ with a heating rate of $10^{\circ} \mathrm{C} \mathrm{min}^{-1}$. The weight loss (TG curve) and its first derivative according to the temperature (DTG curve) were recorded simultaneously.

3.3. 5,6-O-Isopropylidene-1,2-O-(R)-trichloro-ethylidene- $\alpha-D$ glucofuranose (1). A solution of 1,2- $(R)$-trichloroethylidene$\alpha$-D-glucofuranose ( $\alpha$-chloralose) (5.0 g, $16.2 \mathrm{mmol}), 2,2$ dimethoxypropane ( $4 \mathrm{~mL}, 32.4 \mathrm{mmol})$, and PTSA (5 mg) in DMF $(50 \mathrm{~mL})$ was stirred for $24 \mathrm{~h}$ at room temperature. The mixture was neutralized with a $5 \%$ solution of $\mathrm{NaHCO}_{3}$ and the solution was removed. The syrupy residue was crystallized from methanol $(4.72 \mathrm{~g}, 84 \%)$, m.p. $103-105^{\circ} \mathrm{C},[\alpha]_{\mathrm{D}}^{31}-32.0(c$ 1, MeOH). ${ }^{1} \mathrm{H}$ NMR $\left(\mathrm{CDCl}_{3}, 400 \mathrm{MHz}\right): \delta 6.12\left(\mathrm{~d}, 1 \mathrm{H}, J_{1,2}\right.$ $4.0 \mathrm{~Hz}, \mathrm{H}-1), 5.31$ (s, $1 \mathrm{H}, \mathrm{HCCl}_{3}$ ), 4.75 (d, 1H, H-2), 4.59 (ddd, $1 \mathrm{H}, \mathrm{H}-5$ ), 4.45 (dd, $\left.1 \mathrm{H}, J_{4,5} 2.8 \mathrm{~Hz}, \mathrm{H}-4\right), 4.32$ (br d, $1 \mathrm{H}, J_{3,4}$ $3.2 \mathrm{~Hz}, \mathrm{H}-3$ ), 4.16 (dd, $\left.1 \mathrm{H}, J_{6 \mathrm{a}, 6 \mathrm{~b}} 8.8, J_{5,6 \mathrm{a}} 6.4 \mathrm{~Hz}, \mathrm{H}-6 \mathrm{a}\right), 3.96$ 


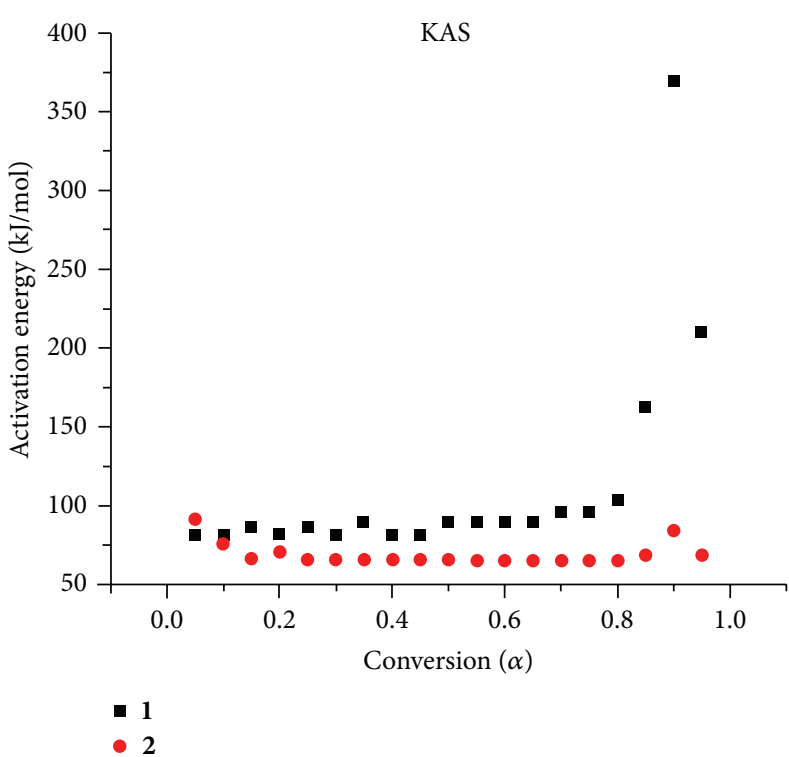

(a)

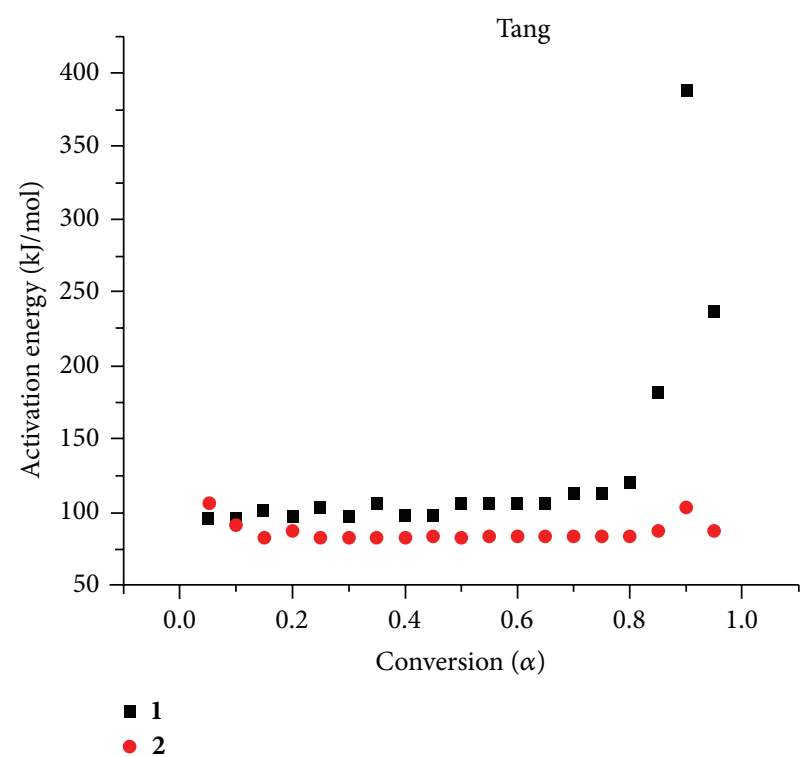

(b)

Figure 4: (a) The plot of activation energy (E) versus the degree of conversion $(\alpha)$ for KAS method of compounds $\mathbf{1}$ and $\mathbf{2}$. (b) The plot of activation energy $(E)$ versus the degree of conversion $(\alpha)$ for Tang method of compounds $\mathbf{1}$ and $\mathbf{2}$.
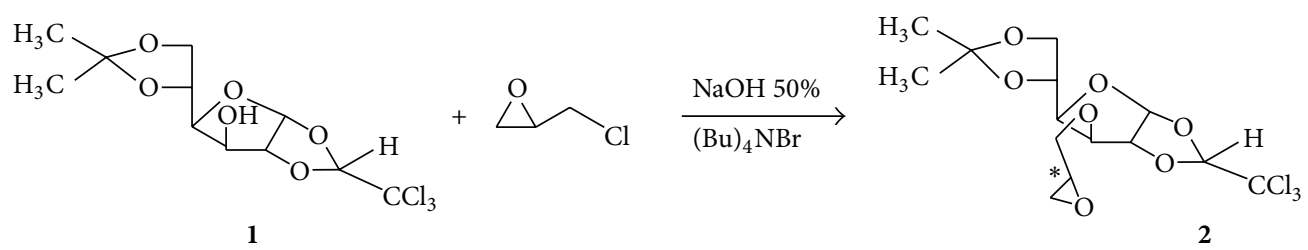

FIGURE 5: The possible reactions of compound 2.

(dd, $\left.J_{5,6 \mathrm{~b}} 5.2 \mathrm{~Hz}, \mathrm{H}-6 \mathrm{~b}\right), 2.65 \mathrm{~d}(\mathrm{br} \mathrm{s}, 1 \mathrm{H}, \mathrm{OH}), 1.42$ (s, 3H, $\mathrm{CH}_{3}$-isop.), 1.35 (s, $3 \mathrm{H}, \mathrm{CH}_{3}$-isop.).

3.4. 5, 6-O-Isopropyliden-1,2-O-(R)-trichloroethylidene-3-O$\left(2^{\prime}, 3^{\prime}\right.$-epoxypropan- $\left.1^{\prime}-y l\right)-\alpha$-D-glucofuranose (2). Epichlorohydrin $(20 \mathrm{~mL}, 256 \mathrm{mmol})$ was stirred with aq $\mathrm{NaOH}$ $(50 \%, 1.25 \mathrm{~mL})$ and tetrabutylammonium bromide $(0.5 \mathrm{~g}$, $1.55 \mathrm{mmol}$ ) for $30 \mathrm{~min}$. 5,6-O-Isopropyliden-1,2-O-(R)-trichloroethylidene- $\alpha$-D-glucofuranose (1) ( $2 \mathrm{~g}, 5.8 \mathrm{mmol})$ was added slowly at approximately $5^{\circ} \mathrm{C}$ under stirring and the reaction was continued at the same temperature for 3 hours, followed by additional 12 hours at room temperature. The reaction mixture was poured over crushed ice and extracted with EtOAc $(4 \times 10 \mathrm{~mL})$; the organic layer was neutralized with aqueous saturated sodium hydrogen carbonate and washed with distilled water $(2 \times 5 \mathrm{~mL})$ and dried over anhydrous $\mathrm{Na}_{2} \mathrm{SO}_{4}$ and filtered. The filtrate was concentrated to give syrup. The syrup was crystallized from hot hexane at $0^{\circ} \mathrm{C}$ to give the pure compound $2(1.75 \mathrm{~g}, 76 \%)$, m.p. $101-102^{\circ} \mathrm{C}$, $[\alpha]_{\mathrm{D}}^{25}-0.20\left(c 1, \mathrm{CH}_{2} \mathrm{Cl}_{2}\right) .{ }^{1} \mathrm{H} \mathrm{NMR}\left(\mathrm{CDCl}_{3}, 400 \mathrm{MHz}\right): \delta$ $6.05\left(\mathrm{~d}, 1 \mathrm{H}, J_{1,2} 4.0 \mathrm{~Hz}, \mathrm{H}-1\right), 5.28\left(\mathrm{~s}, 1 \mathrm{H}, \mathrm{HCCl}_{3}\right), 4.74(\mathrm{~d}, 1 \mathrm{H}$, H-2), 4.65 (m, 1H, H-5), 4.48 (dd, $\left.1 \mathrm{H}, J_{4,5} 2.8 \mathrm{~Hz}, \mathrm{H}-4\right), 4.32$ (br d, $1 \mathrm{H}, J_{3,4} 3.2 \mathrm{~Hz}, \mathrm{H}-3$ ), 4.16 (dd, $1 \mathrm{H}, J_{6 \mathrm{a}, 6 \mathrm{~b}} 8.8, J_{5,6 \mathrm{a}} 6.4 \mathrm{~Hz}$, H-6a), 3.96 (dd, $J_{5,6 b} 5.2 \mathrm{~Hz}, \mathrm{H}-6 \mathrm{~b}$ ), 3.92 (two sets of dd, $1 \mathrm{H}$,
$J_{1^{\prime}, 2^{\prime}} 6.4 \mathrm{~Hz}, \mathrm{H}-1^{\prime}$ ), 3.13 (m, $1 \mathrm{H}, \mathrm{H}-2^{\prime}$ ), 2.80 (two sets of dd, $1 \mathrm{H}$, $J_{2^{\prime}, 3^{\prime}} 11.6 \mathrm{~Hz}, \mathrm{H}-3^{\prime}$ ), 1.39 (s, $3 \mathrm{H}, \mathrm{CH}_{3}$-isop.), 1.33 (s, $3 \mathrm{H}, \mathrm{CH}_{3}$ isop.).

\section{Conclusions}

Two compounds, 5,6-O-isopropylidene-1,2-O-(R)-trichloroethylidene- $\alpha$-D-glucofuranose (compound 1) and the new compound, 5,6-O-isopropylidene-1,2-O- $(R)$ trichloroethylidene - 3-O-(2', $3^{\prime}$ - epoxypropan-1 - yl $)-\alpha-\mathrm{D}$ glucofuranose (compound 2), were synthesized and characterized by FTIR, ${ }^{1} \mathrm{H}$ NMR, and TG-DTA techniques. The thermal degradation of compounds $\mathbf{1}$ and $\mathbf{2}$ in nitrogen is a one-stage reaction according to thermogram. The thermal degradation kinetics of the compounds were evaluated using the KAS and Tang methods. The average activation energies calculated by the KAS method were found to be $96 \mathrm{~kJ} \mathrm{~mol}^{-1}$ for compound 1 and $69 \mathrm{~kJ} \mathrm{~mol}^{-1}$ for compound 2 , respectively, while they were found to be $113 \mathrm{~kJ} \mathrm{~mol}^{-1}$ for compound 1 and $87 \mathrm{~kJ} \mathrm{~mol}^{-1}$ for compound 2 by the Tang method. Thus, it is concluded that thethermal degradation of compound $\mathbf{2}$ is found to be more favorable in comparison to that of compound $\mathbf{1}$. 
The activation energies of the compounds as a function of degree of conversion showed that the compounds degraded in two steps. In the first step which is up to $80 \%$ conversion, $E$ remained almost constant. In the second step, which is between 80 and $100 \%$ conversion, $E$ increased. It is also concluded that thethermal degradation mechanisms of compound 1 and compound $\mathbf{2}$ exhibit similar behavior. Since the new compound (2) exhibits lower thermal degradation characteristics compared to compound (1) without the epoxy ring, it is possible that this could affect the properties of the polymers synthesized using this as a potential monomer.

\section{Conflict of Interests}

The authors declare that there is no conflict of interests regarding the publication of this paper.

\section{Acknowledgment}

The authors thank Professor Dr. Stephen Thomas Astley for checking the English grammar.

\section{References}

[1] J. G. Smith, "Synthetically useful reactions of epoxides," Synthesis, vol. 8, pp. 629-656, 1984.

[2] F. Fringuelli, F. Pizzo, M. Rucci, and L. Vaccaro, "First onepot copper-catalyzed synthesis of $\alpha$-hydroxy- $\beta$-amino acids in water: a new protocol for preparation of optically active norstatines," Journal of Organic Chemistry, vol. 68, no. 18, pp. 7041-7045, 2003.

[3] P. Besse and H. Veschambre, "Chemical and biological synthesis of chiral epoxides," Tetrahedron, vol. 50, no. 30, pp. 8885-8927, 1994.

[4] R. I. Hollingsworth and G. Wang, "Toward a carbohydratebased chemistry: progress in the development of generalpurpose chiral synthons from carbohydrates," Chemical Reviews, vol. 100, no. 12, pp. 4267-4282, 2000.

[5] H. Kunz and K. Rück, "Carbohydrates as chiral auxiliaries in stereoselective synthesis. New synthetic methods," Angewandte Chemie, vol. 32, no. 3, pp. 336-358, 1993.

[6] W. Adam and A. Zhang, "Chiral-auxiliary-controlled diastereoselective epoxidations," Synlett, no. 7, pp. 1047-1072, 2005.

[7] D. E. Levy and P. Fügedi, Eds., The Organic Chemistry of Sugars, Taylor \& Francis, Boca Raton, Fla, USA, 2006.

[8] H. Anıl, L. Yüceer, and T. Yüceer, "1,2- $O$-trichloroethylidene- $\alpha$ D-galactofuranose," Carbohyrate Research, vol. 12, pp. 153-156, 1983.

[9] F. Çetin, N. Yenil, and L. Yüceer, "Stable spiro-endoperoxides by sunlight-mediated photooxygenation of 1,2-O-alkylidene-5(E)eno-5,6,8-trideoxy- $\alpha$-D-xylo-oct-1,4-furano-7-uloses," Carbohydrate Research, vol. 340, no. 17, pp. 2583-2589, 2005.

[10] S. Lee, S. J. Byung, and W. L. Jae, "Thermal degradation kinetics of antimicrobial agent, poly(hexamethylene guanidine) phosphate," Macromolecular Research, vol. 14, no. 5, pp. 491-498, 2006.

[11] D.-Y. Wang, A. Das, A. Leuteritz et al., "Thermal degradation behaviors of a novel nanocomposite based on polypropylene and Co-Al layered double hydroxide," Polymer Degradation and Stability, vol. 96, no. 3, pp. 285-290, 2011.
[12] F. Fraga and E. R. Nũunez, "Activation energies for the epoxy system BADGE $n=0 / m-X D A$ obtained using data from thermogravimetric analysis," Journal of Applied Polymer Science, vol. 80, p. 776, 2001.

[13] H. E. Kissinger, "Reaction kinetics in differential thermal analysis," Analytical Chemistry, vol. 29, pp. 1702-1706, 1957.

[14] T. Akahira and T. Sunose, "Method of determining activation deterioration constant of electrical insulating materials," Research Report Chiba Institute of Technology (Science Technology), vol. 16, pp. 22-23, 1971.

[15] W. Tang, Y. Liu, C. H. Zhan, and C. Wang, "New approximate formula for Arrhenius integral," Thermochimica Acta, vol. 408, pp. 39-43, 2003.

[16] V. Schmidt and V. Soldi, "Influence of polycaprolactone-triol addition on thermal stability of soy protein isolate based films," Polymer Degradation and Stability, vol. 91, no. 12, pp. 3124-3130, 2006. 

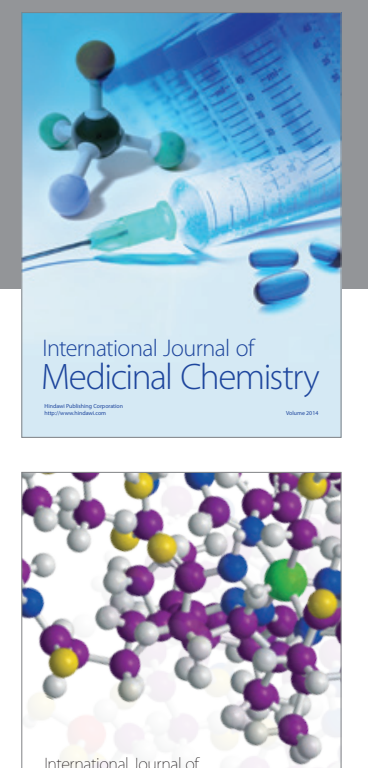

\section{Carbohydrate} Chemistry

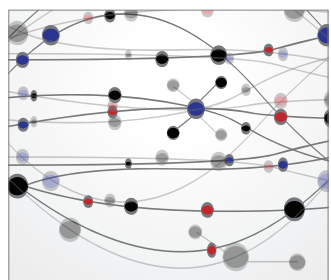

The Scientific World Journal
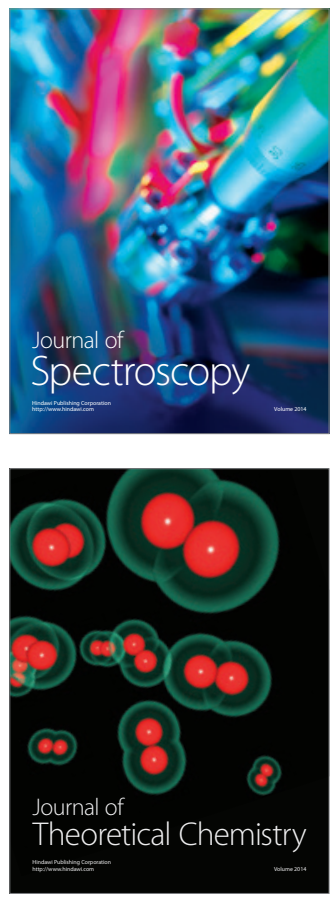
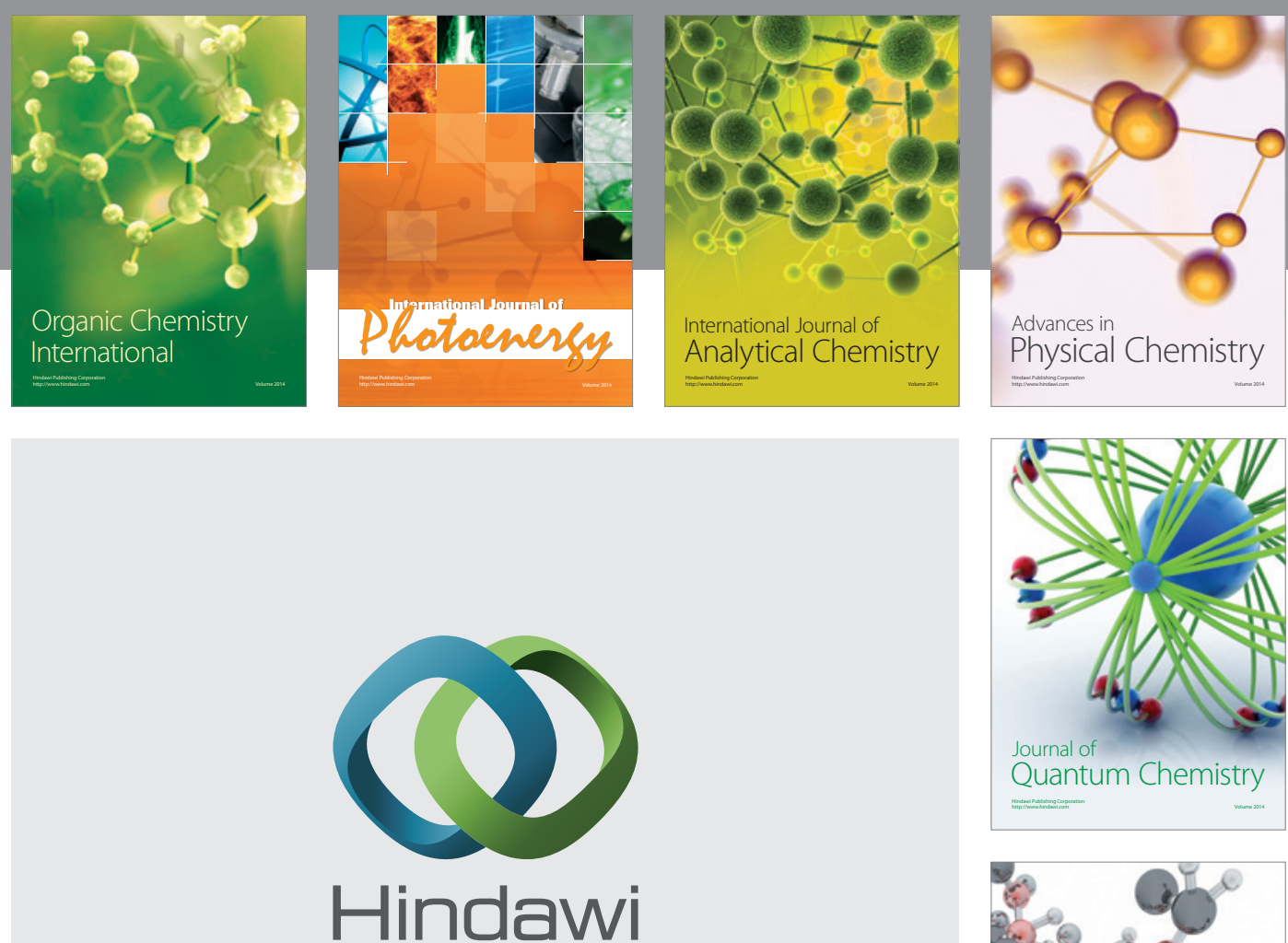

Submit your manuscripts at

http://www.hindawi.com

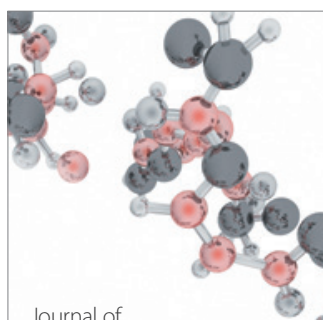

Analytical Methods

in Chemistry

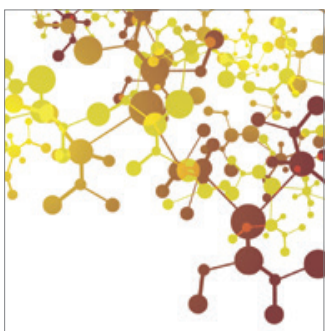

Journal of

Applied Chemistry

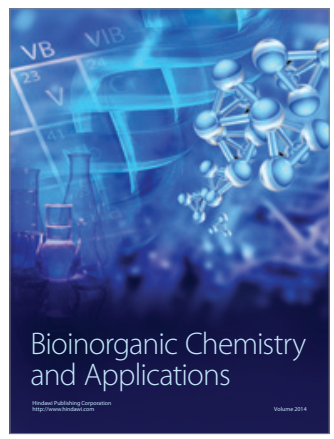

Inorganic Chemistry
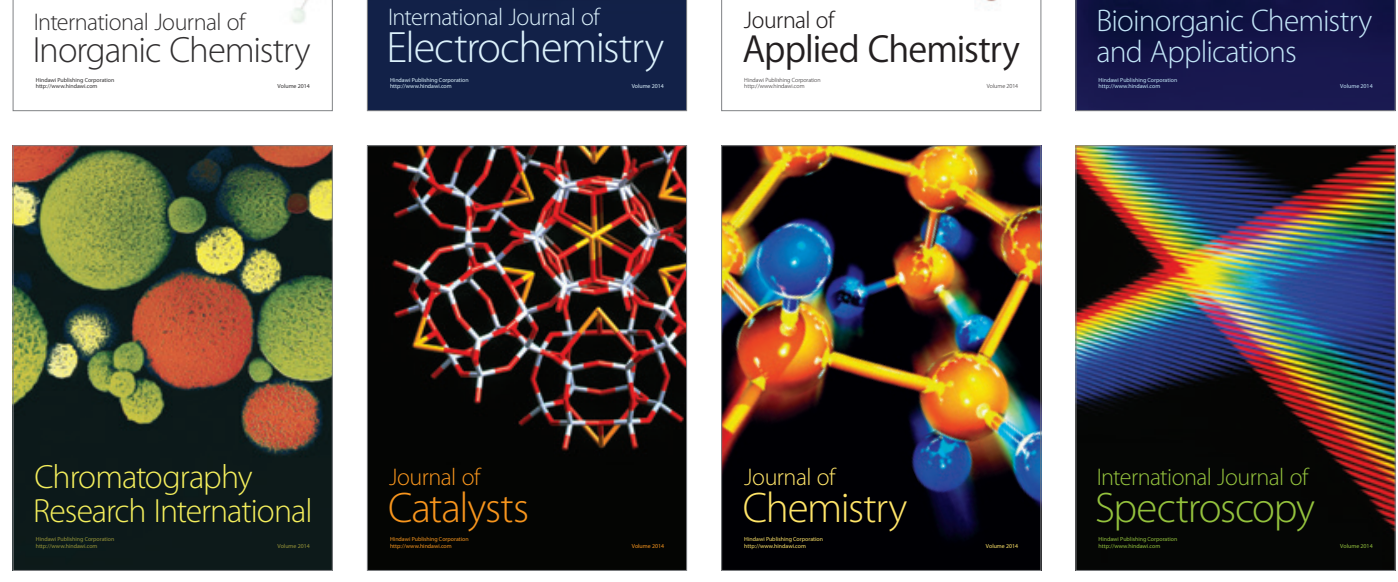